\title{
Effect of Shot Peening on Mechanical Behavior of Zr-Based Bulk Metallic Glasses under Monotonic and Cyclic Loading Mode
}

\author{
Ran Wei ${ }^{1}$, Liangbin Chen ${ }^{2}$, Juan Tao ${ }^{1}$, Shuai Guo ${ }^{1}$, Zhenhua Han ${ }^{3}$ and Fushan $\mathrm{Li}^{1}{ }^{1 *}$ \\ ${ }^{1}$ School of Materials Science and Engineering, zhengzhou University, zhengzhou 450001, China \\ ${ }^{2}$ State Key Laboratory for Mechanical Behavior of Materials, Xi'an Jiaotong University, Xi'an 710049, China \\ ${ }^{3}$ School of Materials Science and Engineering, Xi'an University of Technology, Xi'an 710068, China
}

\begin{abstract}
The mechanical behavior of as-cast and peened $\left(\mathrm{Zr}_{55} \mathrm{Cu}_{30} \mathrm{Ni}_{5} \mathrm{Al}_{10}\right)_{99} \mathrm{Y}_{1}$ bulk metallic glass (BMG) under monotonic loading and cyclic loading mode was investigated. Abundant pre-existing shear bands were observed on the surface of the BMG after shot peening. It is suggested that shot peening can significantly enhance the compressive plasticity of the BMG. Interestingly, compared with the as-cast specimen, the peened specimen exhibits the similar yield stress of about $1850 \mathrm{MPa}$ and fatigue limit of about $1095 \mathrm{MPa}$ in stress range, but shorter fatigue life at high stress level. That is to say, shot peening has a great influence on the fatigue properties of BMG in high stress range, and has little influence on the fatigue properties of BMG in low stress range near fatigue limit. This is attributed to mutually competition between the positive effect and negative effect on the mechanical behaviors of BMG induced by shot peening, and which one of the two effects plays the dominant role depends mainly on the loading mode. The present study will give suggestion for the safe service of Zr-based BMG.

[doi:10.2320/matertrans.M2016349]
\end{abstract}

(Received October 3, 2016; Accepted February 27, 2017; Published April 25, 2017)

Keywords: bulk metallic glasses, fatigue, deformation and fracture, shot peening

\section{Introduction}

Bulk metallic glasses (BMGs) have been considered as potential structural materials due to their superior strength, high elastic limit and excellent corrosion resistance ${ }^{1-4)}$. However, the poor fatigue behavior and plasticity of BMGs limit their engineering application, which remains a great challenge to the materials ${ }^{5-7)}$. The fatigue performance of conventional structural alloys can be enhanced by shot peening ${ }^{8)}$, which is of a reference significance to improve mechanical properties of BMGs. For quasi-static monotonic compression, Greer et $a l .{ }^{5)}$ found that the plasticity of BMGs can be enhanced by compressive residual stress through shot peening treatment. Raghavan et al. ${ }^{9)}$ reported that the shot peening does not cause significant enhancement of the fatigue performance of the BMGs in the four-point bending loading mode. It is worth noting that the fatigue performance of Zr-based BMGs depend strongly on the loading mode ${ }^{10)}$. For example, fatigue limit of Zr-based BMGs in stress range terms under cyclic tensile load was almost three times higher than that under the three-point bending condition ${ }^{10)}$. Up to now, few literatures have simultaneously revealed the effect of shot peening on the plasticity and fatigue behavior of Zr-based BMGs. In this paper, uniaxial monotonic compressive and cyclic compression-compression experiments were conducted on Zr-based BMGs with as-cast and peened state respectively, and the possible micro-mechanism accounting for the research results were discussed.

\section{Experimental Procedure}

$\left(\mathrm{Zr}_{55} \mathrm{Cu}_{30} \mathrm{Ni}_{5} \mathrm{Al}_{10}\right)_{99} \mathrm{Y}_{1}$ alloy was chosen for the current investigation because of its high glass forming ability ${ }^{11)}$. Alloy rods with $3 \mathrm{~mm}$ in diameter $(\Phi)$ and $50 \mathrm{~mm}$ in length $(L)$ were produced by copper mold casting in a high-purity argon

*Corresponding author, E-mail: fsli@zzu.edu.cn atmosphere. The amorphous structure of the rods was identified by X-ray diffraction (XRD). The as-cast rods were shot peened with $4 \mathrm{MPa}$ air pressure and $0.6 \mathrm{~mm}$ diameter steel balls. Peening time of 2 min was chosen for the treatment. Although all the samples were prepared at the same time by the same condition, there still appeared little different peened surface morphology. In order to ensure comparability and reliability, we further selected those samples with the same peening intensity and homogeneity to be used in the experiments, which means the surface was completely peened. The specimens in shape of rod with the size of $\Phi 3 \mathrm{~mm} \times L 6 \mathrm{~mm}$ were well prepared for uniaxial monotonic compressive and cyclic compression-compression tests. The monotonic compressive tests were conducted at strain rates of $10^{-5} / \mathrm{s}$. Cyclic compression-compression were conducted at various stress ranges with an $\mathrm{R}$ ratio $\left(R=\sigma_{\min } / \sigma_{\max }\right.$, where $\sigma_{\min }$ and $\sigma_{\max }$ are the applied minimum and maximum stresses, respectively) of 0.1 at $100 \mathrm{~Hz}$ under a load-control mode. The cyclic loading was terminated in cases the number of cycles reached $1 \times 10^{7}$ where failure did not occurred. At least five samples were tested at fatigue limit stress, due to the fatigue results may depend on the specimen. The fracture morphology of the specimens was observed by scanning electronic microscope (SEM).

\section{Results and Discussions}

Figure 1(a) shows typical stress-strain curves of the as-cast and peened BMG samples. One can see that all samples exhibit nearly an equal yield stress $\sigma_{\mathrm{y}}$ (about $1850 \mathrm{MPa}$ ). However, the plasticity of the as-cast samples is significantly enhanced through shot peening treatment, as evidenced by the increased plastic strain from only $0.5 \%$ to $2.5 \%$. Smaller stress drop amplitude of the peened samples indicates more stable shear deformation. Figure 1(b) and (c) show the fracture lateral surface of as-cast and the peened samples respectively. There are more shear bands in the peened sample than 
that in the as-cast sample, which is consistent with the stressstrain curves in Fig. 1(a).

Mukai et al. ${ }^{12)}$ reported that the localized shear band initiation stress $\left(\sigma_{\mathrm{e}}\right)$ is much lower than the $\sigma_{\mathrm{y}}$ of the BMG samples. In order to clearly present $\sigma_{\mathrm{e}}$ of the BMG samples, the inset in Fig. 1(a) exhibits their enlarged portions bellow its $\sigma_{\mathrm{y}}$. For the as-cast BMG samples, it can be seen that $\sigma_{\mathrm{e}}$ is much lower than its $\sigma_{\mathrm{y}}$, which is in agreement with earlier reports $^{12)}$. In as-cast BMGs, shear bands readily nucleate from stress concentration sites (e.g. rough surface in the process of loading), which induces the low $\sigma_{\mathrm{e}}$. However, for peened BMG samples, it can be seen that shear serrations obviously multiply from $\sigma_{\mathrm{e}}$ to $\sigma_{\mathrm{y}}$, while the corresponding $\sigma_{\mathrm{e}}$ only slightly decreases compared to the as-cast BMG samples. Therefore, the rough surface and pre-existing shear bands created by shot peening on the sample surface are beneficial to shear bands nucleation ${ }^{5}$. Evidently, shot peening could boost shear band nucleation. The compressive residual stress (CRS) induced by shot peening could inhibit the prop-
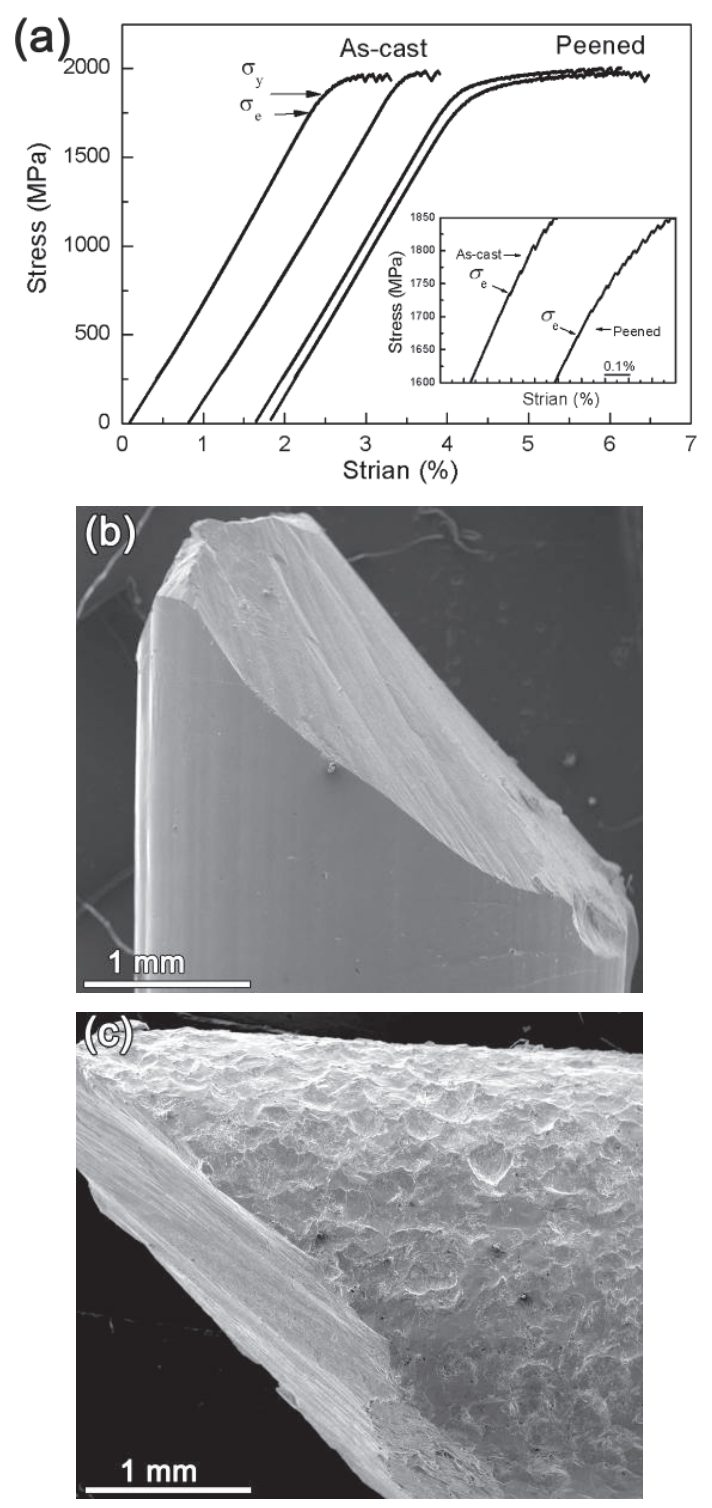

Fig. 1 Monotonic compression stress-strain curves of the as-cast and peened samples. Insets are the enlarged portions of the curves near their $\sigma_{\mathrm{e}}(\mathrm{a})$. Fracture surface of as-cast (b) and peened (c) samples. agation of shear bands in qusi-static compression ${ }^{5)}$, implying that shot peening could promote the proliferation of shear bands under monotonic compression.

The stress range $\left(\sigma_{\mathrm{r}}=\sigma_{\max }-\sigma_{\min }\right)$ is plotted as a function of fatigue cycles to failures $\left(N_{\mathrm{f}}\right)$ for the as-cast and peened samples in Fig. 2(a). The maximum stress range (the material subjected for $10^{7}$ cycles without failure) is defined as the fatigue limit. The peened and as-cast samples exhibit the similar fatigue limit (about $1095 \mathrm{MPa}$ ). However, the fatigue life of the peened samples at high stress level is shorter than that of the as-cast samples. This is contrary to that shot peening could enhance the fatigue performance of crystalline alloys ${ }^{8}$, which is possibly due to the different fatigue mechanisms between BMGs and crystalline alloys.

The fatigue fracture surface of as-cast and peened samples under $\sigma_{\mathrm{r}}$ of about $1197 \mathrm{MPa}$ are shown in Fig. 2(b) and (c). Compared to the samples under monotonic compression (Fig. 1 (b) and (c)), there are many shear bands and some
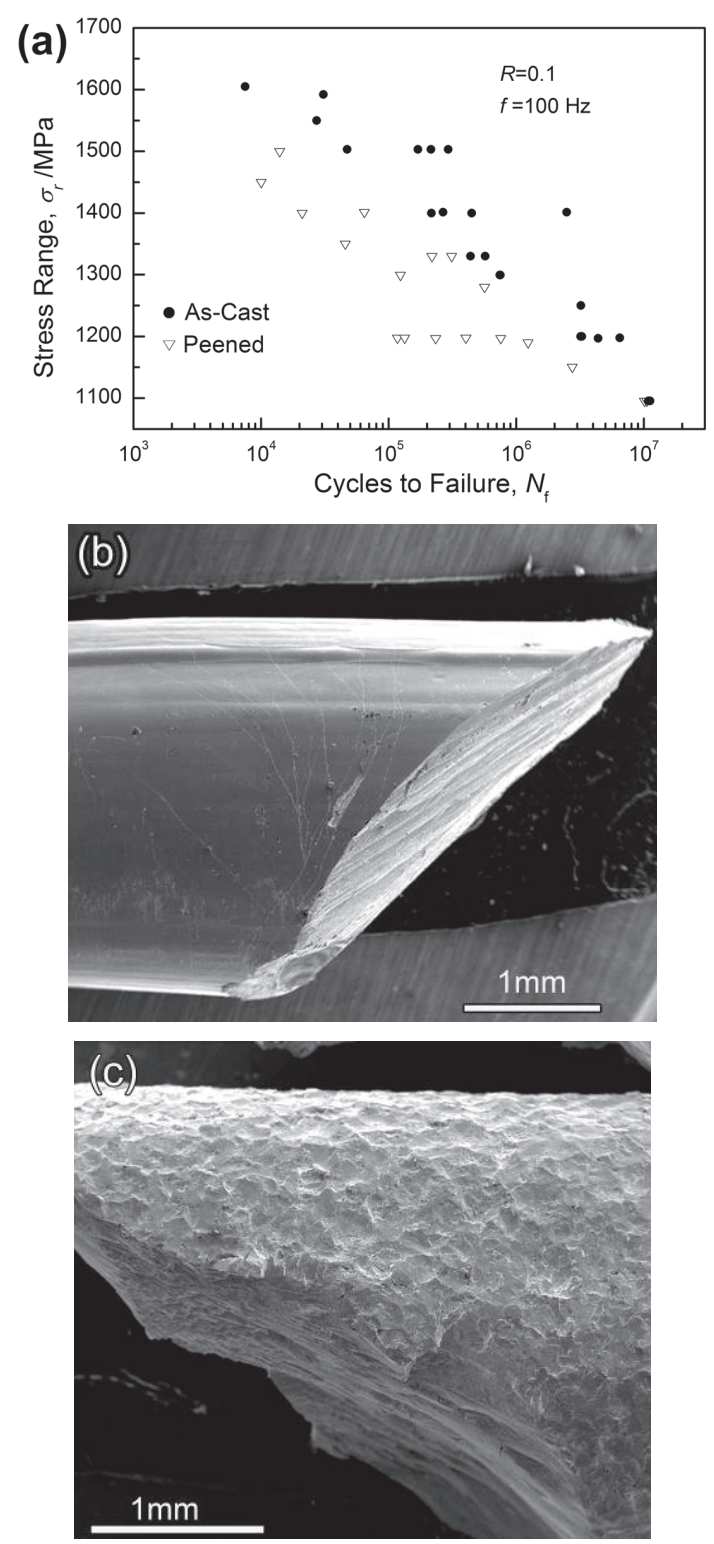

Fig. 2 Stress-life data for the as-cast and peened samples tested at a frequency of $100 \mathrm{~Hz}$ and a load ratio of $R=0.1$ (a). Fatigue fracture surfaces of as-cast (b) and peened (c) samples under $\sigma_{\mathrm{r}}$ of about $1197 \mathrm{MPa}$. 
cracks on the fatigued specimens, indicating that shear band may be easier to initiate under cyclic loading condition than that under monotonic loading, i.e., $\sigma_{\mathrm{e}}$ might be much lower under cyclic loading. This is consistent with the reports in Ref. 2). It is possibly that the decreasing in temperature of the shear zone during unloading process of cyclic loading increases its viscosity, and then accelerates the formation of shear bands in some new sites. In addition, it was obviously that the surface roughness of peened samples (Fig. 1 (c)) was significantly larger than that of the as-cast samples (Fig. 1 (b)).

Figure 3 shows the fatigue fracture morphologies of ascast and peened samples at high stress level. Figure 3 (a) and (d) show overall fatigue fracture morphologies of as-cast and peened samples respectively, which mainly consists of two regions, crack propagation $(\mathrm{P})$ region and fast fracture $(\mathrm{F})$ region. It is obviously seen that the area ratio of $\mathrm{P}$ region in the as-cast sample is larger than that in the peened sample, implying the good fatigue performance of the as-cast sample ${ }^{13)}$. The P region of both as-cast (Fig. 3(b)) and peened (Fig. 3(e)) samples is composed of cracks, striation-like and smooth-like region. In addition, the $\mathrm{P}$ region of the as-cast sample also possesses staircase-like fracture feature, which is a common characteristics of BMGs with excellent fatigue performance ${ }^{3,6)}$. As shown in Fig. 3(c) and (f), the boundary between $\mathrm{F}$ region and $\mathrm{P}$ region is obviously separated by macroscopic crack (as indicated by the arrows), indicating cleavage fracture has occurred before fast fracture. Relatively speaking, striation-like feature occupies most of the area in the $\mathrm{P}$ region for as-cast sample (Fig. 3(c)), whereas the corresponding region in peened sample (Fig. 3 (f)) exhibits smooth-like feature. In short, fatigue fracture morphologies show that the

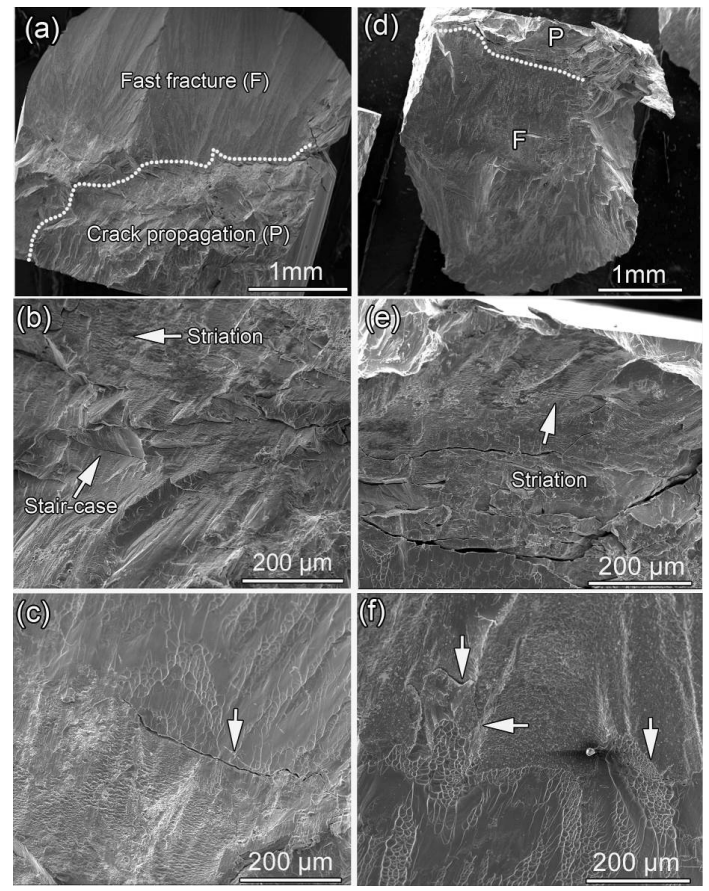

Fig. 3 Fatigue fracture morphologies of as-cast (a)-(c) and peened (d)-(f) samples at $\sigma_{\mathrm{r}}$ of about $1197 \mathrm{MPa}$, the (a) and (d) image showing the overall fatigue fracture surface, (d) and (e) image showing the crack propagation region, and (c) and (f) showing boundary between fast fracture region and crack propagation region. as-cast specimens have better fatigue performance at high stress level.

In general, the mutually competing between the positive effect and negative effect could be induced by shot peening. In monotonic compression, the positive effect such as CRS and pre-existing shear bands could outweigh the negative effect (rough surface), i.e. playing dominant role. Consequently, the plasticity of BMG could be enhanced by shot peening. As well known, the enhanced fatigue performance of conventional alloys is due to that the positive effect (CRS and strain hardening) could exceed the negative effect (rough surface) ${ }^{9)}$. However, the peened layer of the BMGs is softer than the bulk $^{1,5)}$. As mentioned above, the rough surface and pre-existing shear bands could promote shear bands nucleation under cyclic compression. These multiple shear bands could promote fatigue crack nucleate below the surface ${ }^{9)}$ and then propagate along the shear bands ${ }^{2,14}$. That is to say, pre-existing shear bands are negative effect under cyclic compression. In addition, the internal stress at the interface between the peened layer and the bulk might even promote the fatigue crack propagation. Thus, these negative effects would outweigh the positive effect (CRS) in BMGs after shot peening at high stress level. Nevertheless, the CRS could balance the negative effects caused by shot peening at low stress range near fatigue limit, which makes the BMGs exhibit the similar fatigue limit. These micro-mechanisms, however, need further investigation. So, the method of surface shot peening could not enhance fatigue life of BMGs at high stress level. It is suggested that improving the intrinsic toughness of BMGs, such as enhance its Poisson's ratio, could be an effective method to improve its fatigue limit ${ }^{3,15)}$.

\section{Conclusion}

In summary, this study indicates that shot peening could enhance the compressive plasticity of BMGs by promoting the proliferation of shear bands. However, the rough surface and pre-existing shear bands created by shot peening could degrade the fatigue life of BMGs at high stress level, but has little influences on the fatigue properties of BMG in low stress range near fatigue limit due to the compressive residual stress (CRS). This is the result of mutually competition between positive effect (CRS) and negative effect (rough surface and pre-existing shear bands) under cyclic compression condition. The present study suggests that whether or not conducting shot peening treatment on BMGs depends on its application environment.

\section{Acknowledgments}

This work was financially supported by the Young Teacher Special Fund of Zhengzhou University (Grant No. 51099064), and the National Nature Science Foundation of China (Grant No.51401160)

\section{REFERENCES}

1) L. Wang, H. Bei, Y.F. Gao, Z.P. Lu and T.G. Nieh: Acta Mater. 59 (2011) 2858-2864

2) X.D. Wang, R.T. Qu, Z.Q. Liu and Z.F. Zhang: Mater. Sci. Eng. A 627 
(2015) 336-339.

3) Z. Song, Q. He, E. Ma and J. Xu: Acta Mater. 99 (2015) 165-175.

4) Y.H. Chen, J.C. Huang, L. Wang and T.G. Nieh: Intermetallics 41 (2013) 58-62.

5) Y. Zhang, W.H. Wang and A.L. Greer: Nat. Mater. 5 (2006) 857-860.

6) B. Gludovatz, M.D. Demetriou, M. Floyd, A. Hohenwarter, W.L. Johnson and R.O. Ritchie: Proc. Natl. Acad. Sci. USA 110 (2013) 1841918424.

7) C.P. Chuang, T. Yuan, W. Dmowski, G.Y. Wang, M. Freels, P.K. Liaw, R. Li and T. Zhang: Sci. Rep. 3 (2013) 2578.

8) D. Závodská, M. Guagliano, O. Bokůvka and L. Trško: Mater. Today: Proceedings. 3 (2016) 1220-1225.

9) R. Raghavan, R. Ayer, H.W. Jin, C.N. Marzinsky and U. Ramamurty: Scr. Mater. 59 (2008) 167-170.
10) Y. Yue, R. Wang, D.Q. Ma, J.F. Tian, X.Y. Zhang, Q. Jing, M.Z. Ma and R.P. Liu: Intermetallics 60 (2015) 86-91.

11) J. Luo, H. Duan, C. Ma, S. Pang and T. Zhang: Mater. Trans. 47 (2006) 450-453.

12) T. Mukai, T.G. Nieh, Y. Kawamura, A. Inoue and K. Higashi: Intermetallics 10 (2002) 1071-1077.

13) J.W. Qiao, E.W. Huang, G.Y. Wang, H.J. Yang, W. Liang, Y. Zhang and P.K. Liaw: Mater. Sci. Eng. A 563 (2013) 101-105.

14) G.Y. Wang, P.K. Liaw, X. Jin and Y. Yokoyama: J. Appl. Phys. 108 (2010) 113512.

15) G.Y. Wang, P.K. Liaw, Y. Yokoyama, A. Peker, W.H. Peter, B. Yang, M. Freels, Z.Y. Zhang, V. Keppens, R. Hermann, R.A. Buchanan, C.T. Liu and C.R. Brooks: Intermetallics 15 (2007) 663-667. 